\title{
EFEITOS DA INTERTEXTUALIDADE E DA PROSÓDIA NAS CANÇÕES DAS \\ CAMPANHAS PRESIDENCIAIS DE DILMA ROUSSEFF
}

\section{EFFECTS OF INTERTEXTUALITY AND PROSODY IN THE SONGS OF PRESIDENTIAL CAMPAIGNS BY DILMA ROUSSEFF}

\author{
Maria Flávia Figueiredo \\ Professora do Programa de Mestrado em Linguística da Universidade de Franca \\ Líder do Grupo de Pesquisa em Argumentação e Retórica (CNPq) \\ E-mail: mariaflaviafigueiredo@yahoo.com.br
}

\section{Luiz Antonio Ferreira}

Professora do Programa de Mestrado e Doutorado em Língua Portuguesa da Pontifícia Universidade Católica de SP Líder do Grupo de Pesquisa "Estudos de Retórica e Argumentação” (CNPq)

E-mail: luizanferreira@terra.com.br

\section{RESUMO}

Propagandas políticas constituem um terreno fértil para análise, principalmente quando as canções nelas inseridas corroboram seu alcance persuasivo. O objetivo da pesquisa reside em fazer revelar, por meio da análise, a estrutura retórica do corpus selecionado, bem como a prosódia e a intertextualidade que os permeiam. No presente trabalho serão analisados os jingles das campanhas da candidata Dilma Rousseff à presidência em 2010 e em 2014 no horário eleitoral gratuito na TV. Nesse corpus, manifestado por meio da oralidade, os aspectos prosódicos também exercem influência no processo de produção de sentido. Por essa razão, além do arcabouço teórico advindo da Retórica e da Linguística Textual, a presente investigação contará com a contribuição de autores que descrevem os elementos prosódicos e suas respectivas funções linguísticas.

Palavras-chave: Retórica. Prosódia. Intertextualidade. Discurso Político. Jingles.

\begin{abstract}
Political propaganda is a fertile ground for analysis, especially when the songs contained in it corroborate its persuasive reach. The objective of this research is to reveal, through analysis, the rhetorical structure of the selected corpus, as well as prosody and intertextuality that permeates them. In the present work will be analyzed the jingles of the campaigns of the candidate Dilma Rousseff to the presidency in 2010 and in 2014 in the free electoral time in the TV. In this
\end{abstract}


corpus, manifested through orality, the prosodic aspects also exert influence in the process of meaning production. For this reason, in addition to the theoretical framework coming from Rhetoric and Textual Linguistics, the present investigation will count on the contribution of authors who describe the prosodic elements and their respective linguistic functions.

Key-words: Rhetoric. Prosody. Intertextuality. Political speech. Jingles.

\section{INTRODUÇÃO}

O presente trabalho tem como corpus constituinte as canções veiculadas nos vídeos de lançamento das campanhas de Dilma Rousseff à presidência do Brasil nos anos de 2010 e 2014. Por se tratarem de textos orais, ou seja, por se constituírem de palavra cantada, o corpus analisado recebe influência dos aspectos prosódicos manifestados na fala. Nessa interação entre a palavra e a prosódia, acredita-se que a construção de sentido, visando à persuasão, aconteça de forma complexa e carregada de tensões que precisam ser trazidas à tona e investigadas.

Com essa investigação, buscaremos verificar a interdependência dos aspectos puramente verbais e também dos aspectos prosódicos na constituição do alcance persuasivo dos textos analisados, sempre com vistas à adesão do auditório.

Necessariamente interdisciplinar na sua fundamentação teórica, a pesquisa associará ao arcabouço teórico-metodológico da Retórica, reflexões advindas da Fonologia, mais especificamente, da Prosódia. Quanto aos autores utilizados, no que se refere à Retórica, consideraremos as asserções de Aristóteles, Perelman e Olbrechts-Tyteca (2005), Reboul (2004), Meyer (2007) e Abreu (2008). No campo da Prosódia, atentaremos para os estudos de Cagliari (1992), Scarpa (1999) e Figueiredo (2006). Para explorar o campo da Retórica, observaremos o grau de ingerência entre os aspectos que constituem a tríade retórica (ethos, pathos e logos), o contexto de produção e a configuração do auditório. Na análise Prosódica, nos valeremos da escuta dos aspectos suprassegmentais, tais como: a tessitura, a entoação, o acento frasal, o ritmo, a duração, o acento, a pausa, a concatenação, a velocidade de fala e o volume. O diálogo dos textos orais com outros textos (intertextualidade) também será considerado nas investigações, especialmente quando utilizado como estratégia argumentativa. Assim, a intertextualidade presente na primeira canção será contemplada a partir do arcabouço da linguística textual, sobretudo a partir das proposições de Koch (2007), Koch et al. (2007) e Cavalcante (2013). Tais alicerces conduzirão o estudo e propiciarão o entrecruzamento das teorias para a análise das duas canções que constituem o corpus. 
Entre as contribuições deste trabalho está a de se poder compreender, de forma mais clara e significativa, a correlação entre a palavra e o som na constituição da retoricidade dos textos.

\section{PRIMEIRA CANÇÃO - PRESENTE NO VÍDEO DE LANÇAMENTO DA CAMPANHA DE DILMA ROUSSEFF À PRESIDÊNCIA DO BRASIL EM 2010}

No dia 17 de agosto de 2010, iniciou-se o horário eleitoral gratuito no rádio e na TV para os então candidatos à presidência do Brasil. A candidata Dilma Rousseff encerrou seu programa com um jingle de um minuto e meio, cujo refrão foi "deixo em tuas mãos o meu povo". Esse vídeo, destinado apenas à abertura da campanha presidencial, tematiza, de forma antecipada, a passagem do cargo de presidente de Lula para Dilma. Essa temática encontra-se expressa por meio da letra da canção que acompanha o vídeo.

Em função da natureza do corpus, um texto oral, procederemos a uma análise tanto dos aspectos retóricos e prosódicos, como dos aspectos intertextuais nele presentes, entendendo essa intertextualidade também como um recurso retórico, intencionalmente estabelecido.

Vejamos a letra da canção:

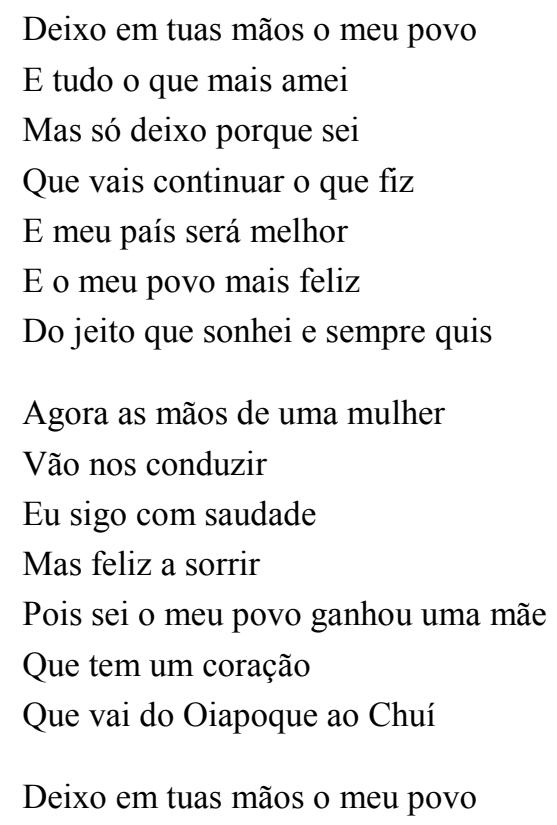

No texto que compõe o jingle, encontramos uma narração em primeira pessoa. A temática é a de uma despedida, isto é, alguém que parte (ou que, forçosamente, precisa partir) e deixa uma responsabilidade para quem vai lhe suceder (ou para quem escolheu para lhe suceder) - a de cuidar do povo brasileiro. Ao se referir a esse povo como seu povo, esse alguém se coloca 
numa posição paternal, como responsável por um grupo, pelo qual fez muito e tem muito apreço. Entretanto, esse alguém se diz tranquilo por ter a certeza de que aquele que vai ocupar o seu lugar dará continuidade ao que fez. Por fim, revela que será nas mãos de uma mulher que deixará o seu povo, apresentando-a como uma mãe. Ao dizer isso, reforça e explicita sua posição como "pai". E, por saber que está deixando o povo nas mãos de uma "mãe", acolhedora e protetora (com "coração que vai do Oiapoque ao Chuí"), parte em paz.

A canção é entoada por uma voz masculina (o que, aliás, faz o auditório identificar o discurso como sendo proferido por um homem), numa interpretação "de violeiro" - uma referência imediata à música regional do Brasil. É interessante observar que, no momento da "revelação" do novo responsável pelo povo, os acordes da viola são substituídos por sons de violinos e bateria, o que faz a canção sair de um tom mais intimista para outro mais vibrante e eufórico.

Vale lembrar que essa estrutura narrativa é também construída no vídeo por meio das imagens que mostram Lula se despedindo do povo e apresentando Dilma à nação brasileira como sua sucessora.

Para descrever alguns aspectos da construção retórica do corpus, faremos uma breve explanação dos conceitos de logos, ethos e pathos.

Aristóteles, na obra Retórica, propõe três dimensões para o entendimento do processo argumentativo, quais sejam: o logos, o pathos e o ethos. O logos é o discurso, ou seja, a argumentação usada pelo orador, os sentidos explícitos ou implícitos, figurativos ou literais da linguagem utilizada. O pathos é entendido como o poder do orador de despertar o auditório para as emoções decorrentes do seu discurso. O ethos refere-se à imagem que o orador expressa para o auditório acerca de si mesmo. Reboul (2004, p. 48) o descreve como "o caráter que o orador deve assumir para inspirar confiança no auditório". Nesse sentido, o ethos retórico caracteriza-se como a imagem, verdadeira ou não, que o orador constrói de si no intuito de persuadir seu auditório. Sendo assim, está relacionado ao caráter do orador e, por isso, não é possível atingir o objetivo de persuadir sem ser, ou pelo menos sem se mostrar ser, um homem de bem.

Se considerarmos, ainda, os conceitos de ethos projetivo e o ethos efetivo, propostos por Meyer (2007)1, podemos concluir que a letra da canção constitui-se numa tentativa clara de fazer com que o ethos construído previamente por Lula (ao longo de dois mandatos) se mesclasse com o ethos ainda incipiente de Dilma. Em outras palavras, o jingle nos transmite a ideia de que o que Lula foi capaz de ser e de fazer terá continuidade no governo de Dilma. Em função disso, podemos afirmar que há um amálgama entre o ethos efetivo de Lula e o ethos preponderantemente projetivo de Dilma. 
Essa projeção do ethos de Lula para Dilma foi também elaborada através de uma intertextualidade com textos bíblicos (em termos linguísticos), o que permite levantar a hipótese de traços messiânicos na constituição desse discurso político, empregados para incitar o pathos no auditório.

Para fundamentar a análise subsequente, façamos algumas considerações acerca do conceito de intertextualidade.

A intertextualidade, que teve sua origem na Teoria Literária durante a década de 1960, é hoje entendida pela Linguística Textual como a relação que um texto estabelece com outros textos anteriormente produzidos. É por meio desse conceito que passamos a compreender que, além das relações com referentes extratextuais, um texto só existe em relação a outros textos produzidos anteriormente.

A esse respeito, Roland Barthes (1974) declara:

O texto redistribui a língua. Uma das vias desta desconstrução é permutar textos, farrapos de textos que existiram ou existem em volta do texto considerado e finalmente dentro dele; todo o texto é um intertexto; outros textos estão presentes nele, em diversos níveis, sob formas mais ou menos reconhecíveis. (BARTHES, 1974, p. 59)

A esse respeito, Julia Kristeva (1970) cunha a expressão "diálogo textual”; conceito que vem mostrar que cada texto só existe em função de outro(s). Por essa razão, a intertextualidade consiste em um horizonte de expectativa sobre o qual o novo texto se inscreve e adquire sentido.

Nas palavras de Koch (2007), a intertextualidade pode ser entendida da seguinte maneira:

Todo texto é um objeto heterogêneo, que revela uma relação radical de seu interior com seu exterior; e, desse exterior, evidentemente, fazem parte outros textos que lhe dão origem, que o predeterminam, com os quais dialoga, que retoma, a que alude, ou a que se opõe. (KOCH, 2007, p. 59)

Na visão de Cavalcante (2013), a relação que um texto estabelece com outros é constitutiva, por essa razão:

Em muitos textos, percebem-se indícios tangíveis de uma relação com outros, desde evidencias tipográficas, que demarcam fronteiras bem específicas entre um dado texto e algum outro que esteja sendo evocado, até pistas mais sutis que conduzem o leitor à ligação intertextual por meio de inferências. (CAVALCANTE, 2013, p. 146)

Para Vigner (1988, p. 33), a intertextualidade "pode dizer respeito a um gênero inteiro [...] ou aplicar-se apenas a uma simples passagem, sob a forma de uma breve alusão, ou de uma simples reminiscência". E é sobre essa noção de intertextualidade como reminiscência de outro texto que nossa análise se debruça. 
$\mathrm{Na}$ letra da canção, podemos encontrar reminiscências do discurso religioso, mais precisamente, da passagem que narra os minutos que precederam a morte de Cristo. Essa narração se encontra no livro de João, capítulo 19, versículos de 25 a 27, das Sagradas Escrituras:

Junto à cruz de Jesus estavam de pé sua mãe, a irmã de sua mãe, Maria, mulher de Cléofas, e Maria Madalena. Quando Jesus viu sua mãe e perto dela o discípulo que amava, disse à sua mãe: "mulher, eis aí teu filho". Depois disse ao discípulo: "eis aí tua mãe". E dessa hora em diante o discípulo a levou para a sua casa. (João 19, 25-27)

Como veremos, a letra da canção estabelece, com o trecho bíblico supracitado, um diálogo intertextual. Primeiramente, transportemo-nos para o cenário descrito no texto bíblico: Jesus, como líder religioso, após concluir sua vida missionária, no momento de sua despedida, confia a João a missão de continuar o que ele havia feito, ou seja, cuidar de sua mãe, de sua igreja, dando assim continuidade ao trabalho que havia iniciado. Essa passagem recebe, na tradição judaico-cristã, a seguinte interpretação: a maternidade de Maria é transferida a João que, naquele momento, representava os fiéis da causa iniciada por Jesus. Por essa razão, na tradição católica, Maria é considerada a mãe da Igreja e, portanto, mãe de todos os cristãos. Já, a letra da canção, também narra a despedida de um líder, não religioso, mas político; mas que, mesmo assim, apresenta-se como redentor de um povo sofrido e necessitado de "salvação". Esse líder político é Lula que, no momento de sua despedida, confia a Dilma a continuidade de sua “missão", na verdade, de seu governo.

Para ratificar o que foi narrado, finalizamos essa primeira análise com um quadro que destaca, em forma de paralelo, a leitura intertextual descrita:

\section{Quadro 1: Paralelo entre a letra da canção e o texto bíblico}

\begin{tabular}{|l|l|}
\hline \multicolumn{1}{|c|}{ LETRA DA CANÇão } & \multicolumn{1}{c|}{ TEXTo BíBLICo } \\
\hline $\begin{array}{l}\text { Deixo em tuas mãos o meu povo } \\
\text { E tudo o que mais amei }\end{array}$ & $\begin{array}{l}\text { Quando Jesus viu sua mãe e perto dela o discípulo que } \\
\text { amava, disse à sua mãe: "mulher, eis aí teu filho". } \\
\text { Depois disse ao discípulo: "eis aí tua mãe". }\end{array}$ \\
\hline $\begin{array}{l}\text { Mas só deixo porque sei } \\
\text { Que vais continuar o que fiz }\end{array}$ & $\begin{array}{l}\text { E dessa hora em diante o discípulo a levou para a sua } \\
\text { casa. }\end{array}$ \\
\hline $\begin{array}{l}\text { E meu país será melhor } \\
\text { E o meu povo mais feliz } \\
\text { Do jeito que sonhei e sempre quis }\end{array}$ & $\begin{array}{l}\text { (Subentende-se que Maria será bem cuidada por João, o } \\
\text { discípulo amado de Jesus.) }\end{array}$ \\
\hline $\begin{array}{l}\text { Agora as mãos de uma mulher } \\
\text { Vão nos conduzir } \\
{[\ldots] \text { sei o meu povo ganhou uma mãe }}\end{array}$ & disse à sua mãe: "mulher, eis aí teu filho". \\
\hline
\end{tabular}

Passemos, então, à análise do jingle que serviu de mote para toda a campanha de 2014. 


\section{SEGUNDA CANÇÃO - PRESENTE NO VÍDEO DE LANÇAMENTO DA CAMPANHA DE DILMA ROUSSEFF À PRESIDÊNCIA DO BRASIL EM 2014}

O objeto da segunda análise do presente trabalho refere-se ao jingle da campanha presidencial da candidata Dilma Rousseff no ano de 2014. Essa canção é entoada por uma voz masculina com um sotaque que evidencia a variedade nordestina da língua portuguesa. Acrescida a essa variedade, identificamos o gênero musical "xote", o que nos remete à cultura nordestina. Vale lembrar que o Nordeste do Brasil configurou-se no maior campo eleitoral da candidata, tanto na eleição de 2010, como na de 2014. Esse fato nos permite inferir que o auditório privilegiado por essa canção, em termos identitários, seria constituído pelos habitantes da região Nordeste.

Ao analisarmos a letra da canção, observamos na parte inicial do discurso, isto é, no exórdio, a apresentação do tema que será reiterado ao longo da campanha em questão. Vejamos como isso se dá:

Dilma, coração valente, força brasileira, garra desta gente.

Dilma, coração valente, nada nos segura pra seguir em frente

Você nunca desviou o olhar do sofrimento do povo

Por isso, eu te quero outra vez

Por isso, eu te quero de novo

Você nunca vacilou em lutar em favor da gente

Por isso eu tô juntinho, do seu lado

Com você e Lula pra seguir em frente

Mulher de mãos limpas (tô com você)

Mulher de mãos livres (tô com você)

Mulher de mãos firmes, vamos viver uma nova esperança

Com muito mais futuro e muito mais mudança

Dilma, coração valente, força brasileira, garra desta gente

Dilma, coração valente, nada nos segura pra seguir em frente

O que tá bom, vai continuar

O que não tá, a gente vai melhorar (2x)

Coração valente!

A princípio, podemos verificar a repetição nos versos "Dilma, coração valente/ Dilma, coração valente". O que observamos é o paralelismo - uma das figuras de repetição. Segundo Koch (2002, p. 123), "a presença de elementos recorrentes produz quase sempre um efeito de intensificação, de ênfase, isto é, tem função retórica". Tal estratégia, presente no exórdio do discurso, objetiva obter a atenção dos ouvintes. 
Ademais, o paralelismo é percebido nos seguintes versos "Força brasileira, garra desta gente/nada nos segura pra seguir em frente". O paralelismo ou isócolo é uma figura de repetição estrutural (cf. FIORIN, 2014, p. 138). Nos versos citados acima, não há uma mera repetição de palavras, verifica-se a ocorrência do paralelismo. Por meio dele, observamos a retomada de uma mesma estrutura oracional que passa a ser preenchida com vocábulos diferentes. Trata-se de um paralelismo semântico, são expressões simétricas no plano das ideias.

Dando continuidade, temos o seguinte excerto:

\author{
Você nunca desviou o olhar do sofrimento do povo \\ Por isso, eu te quero outra vez \\ Por isso, eu te quero de novo \\ Você nunca vacilou em lutar em favor da gente \\ Por isso eu tô juntinho, do seu lado \\ Com você e Lula pra seguir em frente
}

No verso "Você nunca desviou o olhar do sofrimento do povo", pode-se perceber a intenção do orador do discurso/jingle em sensibilizar o auditório/eleitores por meio de um possível sacrifício feito pela candidata à presidência. Do ponto de vista de Perelman e Olbrechts-Tyteca (2005, p. 282-290), o argumento pelo sacrifício é o típico argumento de comparação que utiliza um sistema de trocas para medir o valor atribuído àquilo por que se faz o sacrifício. Nesse sentido, se o sacrifício da presidente ocorreu em função do sofrimento do povo, é criado um processo de indução do raciocínio do auditório. Ora, se o sofrimento do povo não foi negligenciado pela presidente, significa que a mesma valoriza o objeto de seu sacrifício: o povo.

Além disso, identificamos um processo de indução nos seguintes versos: "Você nunca desviou o olhar do sofrimento do povo/ Por isso, eu te quero outra vez. [...] Você nunca vacilou em lutar em favor da gente/ Por isso eu tô juntinho, do seu lado". A indução "é [...] um modo de raciocínio presente na vida cotidiana. Possibilita generalizações corretas, mas permite também chegar a generalizações que são a manifestação de preconceitos, pois temos tendência a generalizar no sentido que nos convém, conscientemente ou não, por razões afetivas ou ideológicas" (FORIN, 2015, p. 59, grifo nosso). A forma como os versos foram construídos induz o auditório a chegar à conclusão de que queremos outra vez a candidata à presidência, já que ela "nunca desviou o olhar do sofrimento do povo". O conectivo de conclusão "por isso" contribui também para a indução do auditório para a conclusão estabelecida pelo orador.

No último verso da estrofe em análise, foi identificado o argumento de autoridade: "Com você e Lula pra seguir em frente". Ao associar o ex-presidente Lula à campanha presidencial visando à reeleição de Dilma Rousseff, o orador teve como objetivo fortalecer sua tese. Perelman e Olbrechts-Tyteca (2005, p. 348) afirmam: “o argumento de prestígio mais 
nitidamente caracterizado é o argumento de autoridade, o qual utiliza atos ou juízos de uma pessoa [...] como meio de prova a favor de uma tese". Ademais, nesse verso, o ethos de Lula atua como um princípio e como um argumento de autoridade (MEYER, 2007) e, quando associado ao nome de Dilma, contribui para a construção do ethos da candidata, como se ela fosse uma extensão do ex-presidente Lula.

Na próxima estrofe deparamo-nos, mais uma vez, com a repetição:

\author{
Mulher de mãos limpas (tô com você) \\ Mulher de mãos livres (tô com você) \\ Mulher de mãos firmes, vamos viver uma nova esperança \\ Com muito mais futuro e muito mais mudança
}

Tanto Perelman e Olbrechts-Tyteca (1996) como Reboul (2004) consideram a repetição uma figura de presença, pois, por meio dela, o auditório pode sentir melhor o argumento. Nos versos "Mulher de mãos limpas/ Mulher de mãos firmes/ Mulher de mãos livres" é evidenciada a figura de presença, uma vez que, pela repetição, o auditório fixa a mensagem na mente.

Na peroração, ou seja, na conclusão do jingle temos:

O que tá bom, vai continuar

O que não tá, a gente vai melhorar $(2 \mathrm{x})$

Coração valente!

A princípio percebemos uma ligação de sucessão nos versos "O que tá bom, vai continuar/ O que não tá, a gente vai melhorar". Dentre as relações de sucessão estão aquelas de vínculo causal, ou seja, sendo dado um acontecimento, tendem a evidenciar o efeito que dele deve resultar (PERELMAN; OLBRECHTS-TYTECA, 2005). Nesse sentido, de acordo com a argumentação proposta no jingle, "o que tá bom" refere-se a acontecimentos, a melhorias; sendo assim, os resultados positivos manter-se-ão como numa relação sucessiva. Ademais, se algo ainda não está bom, pelo mesmo raciocínio infere-se que assim como outras questões foram melhoradas, as que ainda não foram receberão o mesmo tratamento.

No último verso da peroração do discurso, temos a reiteração do tema da campanha: “Coração valente!". A expressão "Coração valente" - representando a candidata à presidência Dilma Rousseff - constitui-se numa metonímia, isto é, numa difusão semântica. No eixo da extensão, um valor semântico transfere-se a outro, num espalhamento sêmico.

Com isso, no eixo da intensidade, ela dá uma velocidade maior ao sentido, acelerandoo, pois, ao enunciar, por exemplo, um efeito, já se enuncia também a causa, suprimindo etapas enunciativas. Ao dar ao sentido aceleração, a metonímia tem um valor argumentativo muito forte. O que estabelece uma compatibilidade entre os dois sentidos é uma contiguidade, ou seja, uma proximidade, uma vizinhança, um contato (FIORIN, 2015, p. 37, grifos nossos). 
Assim, a carga semântica da expressão "Coração Valente” é difundida para o caráter global da candidata. Esse sentido é, inclusive, reforçado pelo nível sintático, uma vez que a expressão aparece, na frase, como um aposto explicativo.

Uma vez apresentada a análise argumentativa da letra do jingle, faremos uma breve menção a alguns aspectos prosódicos que se evidenciaram na constituição melódica da canção. Para isso, elencaremos os elementos prosódicos que ocorrem na língua portuguesa seguidos das funções linguísticas que podem exercer.

O termo prosódia recobre uma ampla gama de fenômenos fônicos que abarcam os parâmetros de altura melódica (tessitura, entoação, tom e acento frasal), de duração (ritmo, duração, acento, pausa, concatenação e velocidade de fala) e de intensidade sonora (volume). Cada um desses elementos prosódicos pode desempenhar, no discurso, diferentes funções linguísticas. Portanto, não é suficiente conhecer cada um deles, mas se faz imprescindível descriminar também as possíveis funções linguísticas por eles exercidas, pois são elas que permitirão a construção do sentido do enunciado. (FIGUEIREDO, 2006). De acordo com Cagliari (1992), os elementos prosódicos podem exercer, no discurso, distintas funções

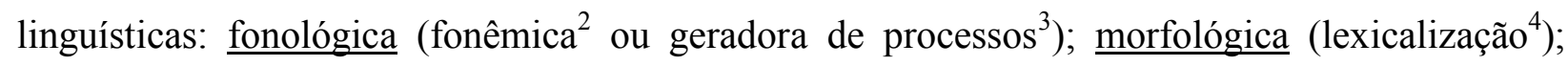
sintática (categorias e funções); discursiva (coesiva); dialógica (turnos conversacionais); semântica (conotações, subentendidos); pragmática (atitudes do falante); identificação do falante ou da língua; reestruturação da produção da fala e fonética (fatos físicos).

Fundamentados nesse viés teórico, podemos verificar que há incidência relevante de elementos prosódicos em, pelo menos, dois versos do jingle analisado. Vejamos o primeiro deles:

Você nunca desviou // o olhar // do sofrimento do povo ${ }^{5}$

Nesse verso, ocorre pausa em dois momentos, pausas essas motivadas pela estrutura rítmica da canção. Em teoria, a pausa pode exercer, no discurso, as seguintes funções linguísticas:

a) função semântica (conotações, subentendidos)

- Mudança brusca do conteúdo semântico.

b) função pragmática (atitudes do falante)

- O uso de pausas "fora do esperado" demonstra uma atitude do falante para impressionar o interlocutor. 
- Falar destacando as palavras com pausas demonstra que o falante deseja reforçar sua autoridade e/ou o valor do que diz.

- Serve para chamar a atenção para o que se vai dizer em seguida.

No trecho em questão, a primeira pausa pode levar o ouvinte a esperar tanto uma mudança brusca do conteúdo semântico (função semântica), quanto uma chamada de atenção para o que se vai dizer em seguida (função pragmática). Em ambos os casos, a pausa fornecerá ao ouvinte o tempo suficiente para imaginar o que será dito adiante. O que nos chama a atenção, porém, é o verbo utilizado antes da pausa: desviou. O uso desse verbo, dentro do contexto sociopolítico em que a canção foi enunciada, pode apresentar uma carga semântica negativa, ou seja, pode trazer à tona a memória recente do ouvinte, levando-o a relacioná-lo aos contextos de "desvio de verbas", "desvio de recursos", dentre outros. Nesse caso, o ouvinte pode, por um instante, imaginar que a letra se propõe a fazer uma defesa da candidata, o que se desfaz, em seguida, quando o restante da frase é enunciado. Porém, essa falsa impressão pode acompanhar o ouvinte, causando nele uma sensação de que a candidata precisaria se justificar diante dos casos de corrupção que se deflagraram em seu primeiro mandato.

O segundo verso que merece uma análise prosódica é o seguinte:

Com você e Lula pra seguir em frente

Nesse trecho, os elementos prosódicos relevantes incidem sobre a palavra "Lula". Nela, podemos observar a apresentação de volume baixo, velocidade de fala acelerada e tessitura grave. A incidência conjunta desses três elementos prosódicos nos permite fazer a seguinte interpretação dentro do contexto em que foi enunciado: o nome do ex-presidente Lula não deixou de ser mencionado, porém, em termos prosódicos, essa menção se deu de modo a gerar um apagamento. Isso pode ser afirmado em vista das funções linguísticas que o uso desses elementos prosódicos carreia. $\mathrm{O}$ volume baixo, por exemplo, pode estar relacionado à diminuição da relevância daquilo que está sendo dito. A velocidade de fala mais lenta pode sinalizar menor ênfase ao que se diz. O Uso de tessitura grave pode estar relacionado a digressões, isto é, a fuga do tema principal (que, no caso, seria a candidata Dilma).

A leitura prosódica desse verso nos permite inferir que houve uma tentativa de apagamento da figura de Lula na segunda campanha de Dilma à presidência quando comparada à sua relevância na primeira campanha. 


\section{CONSIDERAÇÕES FINAIS}

Acreditamos que os resultados aqui apresentados evidenciaram o cumprimento do objetivo proposto, qual seja, o de fazer revelar, por meio da análise, a descrição retórica do corpus selecionado, bem como a intertextualidade e a prosódia que o permeia.

Buscou-se, por meio da investigação realizada, desvelar as relações que a letra da primeira canção estabelece com outros textos. E, como vimos, os resultados da análise apontaram a presença de marcas de religiosidade que evidenciam a intertextualidade do corpus com textos bíblicos, o que permitiu rastrear a presença de traços messiânicos na constituição desse discurso político.

A utilização de técnicas argumentativas, como a repetição, a indução e as ligações de sucessão, evidenciou igualmente o caráter persuasivo da letra da segunda canção. Paralelamente, os elementos prosódicos analisados demonstraram sua força argumentativa na constituição do discurso.

Verificou-se, ainda, que, em termos persuasivos, as letras das canções intencionaram agrupar estratégias retóricas que pudessem conferir a Lula e, consequentemente, a Dilma, a imagem de pessoa(s) do bem. A criação adequada dessa imagem (ethos) inspiraria a confiança no auditório e garantiria, por parte deste, o convencimento almejado, ou seja, a votação maciça em ambas as eleições.

\section{NOTAS}

1 O ethos projetivo é um imanente, ou seja, é a primeira imagem que o auditório forma do orador e a primeira imagem que o orador forma do auditório. Em outras palavras, é aquele que o outro da relação retórica projeta como imagem. Tanto o orador quanto o auditório projetam no outro uma imagem a priori, que representa o ethos projetivo. No entanto, a imagem realmente construída pelo orador, visando persuadir o auditório, é a imagem efetiva, ou seja, o ethos efetivo.

2 Certos fonemas se caracterizam por meio de elementos prosódicos, tais como o tom (em línguas tonais), a duração (no italiano) e o acento (na língua portuguesa).

3 As alterações sonoras que ocorrem nas formas básicas dos morfemas, ao se realizarem foneticamente, são explicadas através de regras que caracterizam os processos fonológicos (cf. CAGLIARI, 2002, p. 99). Alguns exemplos de processos fonológicos gerados pela prosódia são: a palatalização, a labialização, a nasalização, a assimilação, a contração e até mesmo o uso de um "creaky voice" em determinados contextos.

4 Ocorre a "lexicalização" quando palavras são definidas por meio de elementos prosódicos.

5 A pausa é representada pelas barras invertidas (//). 


\section{REFERÊNCIAS}

ARISTÓTELES. Retórica. Prefácio e introdução de Manuel Alexandre Júnior, tradução e notas de Manuel Alexandre Júnior, Paulo Farmhouse Alberto e Abel do Nascimento Pena. 2. ed. revista. Lisboa: Imprensa Nacional-Casa da Moeda, 2005.

BARTHES, R. Verbete “Texte”. Encyclopaedia Universalis, 1974.

A retórica da imagem. In: O óbvio e o obtuso. Rio de Janeiro: Nova Fronteira, 1990. p. 27-41.

BÍBLIA CATÓLICA. Versão eletrônica 1.0, 2005.

CAGLIARI, L. C. Prosódia: algumas funções dos supra-segmentos. Cadernos de Estudos Linguísticos, Campinas, n. 23, p. 137-151, jul./dez. 1992.

CAGLIARI, L. C. Análise fonológica: introdução à teoria e à prática, com especial destaque para o modelo fonêmico. Campinas: Mercado de Letras, 2002. (Coleção Idéias sobre Linguagem).

CAVALCANTE, M. M. Os sentidos do texto. São Paulo: Contexto, 2013.

DONDIS, D. A. Sintaxe da linguagem visual. Tradução de Jefferson Luiz Camargo. 3. ed. São Paulo: Martins Fontes, 2007.

FIGUEIREDO, M. F. (BOLLELA, M. F. F. P.) A prosódia como instrumento de persuasão. In: LOUZADA, M. S. O.; NASCIMENTO, E. M. F. S.; OLIVEIRA, M. R. M.. (Orgs.). Processos enunciativos em diferentes linguagens. Franca: UNIFRAN, 2006. p. 113-128. (Coleção Mestrado, 1)

FIGUEIREDO, M. F.; VERZOLA, M. G. O ethos feminino no primeiro discurso de Dilma Rousseff como presidente eleita do Brasil. In: XVI Congreso Internacional de la Asociación de Lingüistica y Filología de la América Latina (ALFAL), 2011, Alcalá de Henares. Actas del XVI Congreso Internacional de la Asociación de Lingüistica y Filología de la América Latina (ALFAL). Alcalá de Henares: Editora da Universidad de Alcalá, 2011. p. 1023-1032.

FIORIN, J. L. Argumentação. São Paulo: Contexto, 2015.

FIORIN, J. L. Figuras de retórica. São Paulo: Contexto, 2014.

HOUAISS, A. Dicionário eletrônico da língua portuguesa. Versão 1.0. Rio de Janeiro: Objetiva, 2001.

Jingle de abertura da campanha da candidata Dilma Rousseff. Disponível em: $<$ https://www.youtube.com/watch?v=Gqu2HjbFEGo\&hd=1>. Acesso em: 1'. nov. 2011.

Jingle de abertura da campanha da candidata Dilma Rousseff. Disponível em: $<$ https://www.youtube.com/watch?v=3k8YQCSs8es>. Acesso em: 10 nov. 2014.

KOCH, I. V. Os gêneros do discurso. In: Desvendando os segredos do texto. São Paulo: Cortez, 2002.

KOCH, I. G. V. O texto e a construção dos sentidos. 9. ed. São Paulo: Contexto, 2007. 
KOCH, I. G. V.; BENTES, A. C.; CAVALCANTE, M. M. Intertextualidade: diálogos possíveis. São Paulo: Cortez, 2007.

KRISTEVA, J. Le texte du roman. La Haye: Mouton, 1970.

MEYER, M. A retórica. Tradução de Marly N. Peres. São Paulo: Ática, 2007.

MEYER, M. Questões de retórica: linguagem, razão e sedução, Lisboa: Edições 70, 1998.

PERELMAN, C.; OLBRECHTS-TYTECA L. Tratado da argumentação: a nova retórica. Tradução de Maria Ermantina de Almeida Prado Galvão. 2. ed. São Paulo: Martins Fontes, 2005.

REBOUL, O. Introdução à retórica. Tradução de Ivone Castilho Benedetti. 2. ed. São Paulo: Martins Fontes, 2004.

TRINGALI, D. Introdução à retórica: a retórica como crítica literária. São Paulo: Duas Cidades, 1988.

VIGNER, G. Intertextualidade, norma e legibilidade. In: GALVES, C.; ORLANDI, E. P.; OTONI, P. (Orgs.). O texto: escrita e leitura. Campinas: Pontes, 1988. p. 31-37. 